\title{
Stromal Cell-Derived Factor-1 $\alpha$ Alleviates Calcium-Sensing Receptor Activation-Mediated Ischemia/Reperfusion Injury by Inhibiting Caspase-3/Caspase-9-Induced Cell Apoptosis in Rat Free Flaps
}

\author{
Li Song, ${ }^{1}$ Li-Na Gao, ${ }^{1}$ Jun Wang, ${ }^{1}$ Swosti Thapa, ${ }^{2}$ Yong Li, ${ }^{2}$ Xiao-Bo Zhong, \\ Hong-Wei Zhao, ${ }^{2}$ Xue-Rong Xiang, ${ }^{1,3}$ Fu-Gui Zhang $\mathbb{D}^{1,2}$ and Ping Ji ${ }^{10}{ }^{1,2}$ \\ ${ }^{1}$ Chongqing Key Laboratory for Oral Diseases and Biomedical Sciences, Chongqing 401147, China \\ ${ }^{2}$ Department of Oral and Maxillofacial Surgery, Stomatological Hospital of Chongqing Medical University, Chongqing 401147, China \\ ${ }^{3}$ Chongqing Municipal Key Laboratory of Oral Biomedical Engineering of Higher Education, Chongqing 401147, China
}

Correspondence should be addressed to Fu-Gui Zhang; 500290@hospital.cqmu.edu.cn and Ping Ji; pingji1962@163.com

Received 20 July 2017; Revised 21 September 2017; Accepted 15 October 2017; Published 11 January 2018

Academic Editor: Sabrina Corbetta

Copyright (C) 2018 Li Song et al. This is an open access article distributed under the Creative Commons Attribution License, which permits unrestricted use, distribution, and reproduction in any medium, provided the original work is properly cited.

\begin{abstract}
Surgical flaps are frequently affected by ischemia/reperfusion (I/R) injury. Calcium-sensing receptor (CaSR) and stromal cellderived factor- $1 \alpha$ (SDF-1 $\alpha)$ are closely associated with myocardial I/R injury. This study was performed to evaluate the feasibility of applying SDF- $1 \alpha$ to counteract CaSR activation-mediated I/R injury in ischemic free flaps. Free flaps that underwent ischemia for $3 \mathrm{~h}$ were equally randomized into five groups: $\mathrm{CaCl}_{2}, \mathrm{NPS} 2143+\mathrm{CaCl}_{2}, \mathrm{SDF}-1 \alpha+\mathrm{CaCl}_{2}, \mathrm{AMD} 3100+\mathrm{SDF}-1 \alpha+\mathrm{CaCl}$, and normal saline. The free flaps were harvested to evaluate flap necrosis and neovascularization after $2 \mathrm{~h}$ or $7 \mathrm{~d}$ of reperfusion. $\mathrm{p}$ $\mathrm{CaSR} / \mathrm{CaSR}$ was extensively expressed in vascular endothelial cells of free flaps after I/R injury, and activation of the SDF-1 $\alpha / C X C R 4$ axis and NPS2143 could reduce the expression of cleaved caspase-3, caspase-9, FAS, Cyt-c, and Bax and increase Bcl-2 expression; the opposite was true after CaSR activation. Interestingly, initiation of the SDF-1 $\alpha /$ CXCR 4 axis might abrogate CaSR activationinduced I/R injury through enhancement of microvessel density. In conclusion, CaSR might become a novel therapeutic target of free flaps affected by I/R injury. Activation of the SDF-1 $\alpha /$ CXCR 4 axis and NPS2143 could counteract CaSR activation-mediated I/R injury and promote free flap survival through inhibition of caspase-3/caspase-9-related cell apoptosis and enhancement of neovascularization.
\end{abstract}

\section{Introduction}

Surgical flaps are frequently used to repair defects caused by congenital diseases, trauma, or tumor excisions in plastic and reconstructive surgery. However, partial or total necrosis of flaps after early ischemia is commonly encountered $[1,2]$. Ischemia/reperfusion ( $\mathrm{I} / \mathrm{R})$ injury is considered the primary cause of flap necrosis [3].

Calcium-sensing receptor (CaSR), which was originally cloned from parathyroid chief cells by Brown et al. in 1993 [4], is expressed in various tissues and organs such as the myocardium, brain, lung, and kidney $[5,6]$. Increasing evidence has demonstrated that CaSR is associated with cell apoptosis and "calcium overload," causing I/R injury $[7,8]$. Recent studies have suggested that CaSR is also expressed in vascular smooth muscle cells [9], human umbilical vein endothelial cells [10], porcine coronary artery endothelial cells [11], and the rabbit superior mesenteric artery [12], but not in the vascular endothelial cells of skin flaps.

Stromal cell-derived factor-1 (SDF-1), which belongs to the CXC chemokine family, was initially characterized as a pre-B-cell stimulatory factor and cloned from mouse bone marrow stromal cells by Nagasawa et al. in 1994 [13]. SDF-1 is well known for its promotional function in neovascularization, including angiogenesis and vasculogenesis. For example, SDF-1 plays a critical role in angiogenesis 
by regulating endothelial sprouting in vitro and in vivo [14]; this can significantly reduce ischemic free flap necrosis $[15,16]$, as we previously reported [17]. SDF-1 also confers protection against myocardial I/R injury with less apoptotic cell death [18]. However, no previous studies have shown either protection against I/R injury or an antiapoptotic effect by SDF-1 in skin flaps.

This study was performed to determine whether CaSR is functionally expressed in the vascular endothelial cells of free flaps and plays a critical role in $I / R$ injury of free flaps. The authors also assessed whether the administration of SDF- $1 \alpha$ can protect free flaps against I/R injury and alleviate CaSR activation-mediated I/R injury in rat free flaps. Finally, whether the above effects can be neutralized by the CXCR4 antagonist AMD3100 was also examined.

\section{Materials and Methods}

2.1. Establishment of Oversized Epigastric Axial Skin Flap Model to Mimic Free Flap Model. This study was approved by the Chongqing Medical University Medical Center Institutional Animal Care and Use Committee. Male SpragueDawley rats (Central Animal Laboratory of Chongqing Medical University) weighing 220 to $280 \mathrm{~g}$ were housed under specific pathogen-free conditions and treated according to National Institutes of Health guidelines. Specialists at Chongqing Medical University monitored the health of the animals weekly. The rats were anesthetized by intraperitoneal injection of sodium pentobarbital $(30 \mathrm{mg} / \mathrm{kg})$ as previously described [19]. The right superficial epigastric artery- and vein-based epigastric axial skin flaps were approximately 5 $\times 6 \mathrm{~cm}$ in size and comprised skin and subcutaneous fascia, including the panniculus carnosus, as previously described [17], while the opposite superficial epigastric vessels were ligated [20]. All rats were equally randomized into Groups A, B, $\mathrm{C}, \mathrm{D}$, and $\mathrm{E}$ ( $n=10$ per group), in which they received $\mathrm{CaCl}_{2}$ (0.1 mL/kg; Sigma-Aldrich, St. Louis, MO, USA), NPS2143 (1 mg/kg; Selleck Chemicals, Houston, TX, USA) $+\mathrm{CaCl}_{2}$, SDF-1 $\alpha(10 \mathrm{mg} / \mathrm{kg}$; Cyagen Biosciences, Santa Clara, CA, $\mathrm{USA})+\mathrm{CaCl}_{2}, \mathrm{AMD} 3100$ (5 mg/kg; Sigma-Aldrich) + SDF$1 \alpha+\mathrm{CaCl}_{2}$, and normal saline (NS) only, respectively [21]. The second reagents were administrated through the femoral vein 10 min after the first treatment and 10 min earlier than the third treatment. A $3 \mathrm{~h}$ period of flap ischemia was elected among different time points (i.e., hours 1, 2, 3, and 4) based on the highest expression of phosphorylated CaSR (p-CaSR) protein (Supplemental Figure 1). Upon completion of a $3 \mathrm{~h}$ period of ischemia induced by clamping the pedicle vessels with double microvascular clamps [22] to mimic ischemia of free flaps, the clamps were removed, and all of the free flaps were sutured to the original sites with interrupted 5-0 Ethilon (Ethicon, Inc., Somerville, NJ, USA). The rats recovered from anesthesia in a $20^{\circ} \mathrm{C}$ to $25^{\circ} \mathrm{C}$ environment before they were returned their feeding cages, and penicillin $(200,000 \mathrm{U} / \mathrm{d})$ was intramuscularly administered for $3 \mathrm{~d}$ thereafter. The rats' diet, mental status, and flap survival were observed and recorded daily. The free flaps were harvested after $2 \mathrm{~h}$ or $7 \mathrm{~d}$ of reperfusion ( $n=5$ per group), and all rats were killed by an overdose of sodium pentobarbital.

2.2. Evaluation of Free Flap Survival. The flaps were photographed on postoperative day 7. The survival status of the free flaps was blindly assessed with respect to their color, presence of bleeding upon cutting, gross appearance, and area, even if covered with scar tissue. The area of survival and total flap surface area were evaluated using Image-Pro Plus software (version 5.0; Media Cybernetics LP, Silver Spring, $\mathrm{MD}, \mathrm{USA}$ ). The necrotic ratio was expressed as the percentage of necrotic area relative to the total flap surface area as previously described [17]. The tissues harvested from the conjunctive areas between the flaps and the recipients were cut into $5 \mu \mathrm{m}$ thick paraffin sections or prepared for other assays.

2.3. Western Blot Analysis. Western blot analysis was conducted as previously described [17, 23]. Briefly, tissues from the conjunctive area were collected, lysed in modified RIPA buffer, centrifuged, and quantified using the Bradford method (Beyotime, Shanghai, China). After quantification of the protein concentration, equal amounts of protein lysate were separated by sodium dodecyl sulfate-polyacrylamide gel electrophoresis according to established protocols. The proteins were transferred from the gels to PVDF membranes (Pall, Port Washington, NY, USA) in a sandwich model at $200 \mathrm{~mA}$ for $90 \mathrm{~min}$. The membranes were then placed in TBS/T, probed with antibodies to p-CaSR (1:500; Bioworld Technology, St. Louis Park, MN, USA), CXCR4 (1:200; Santa Cruz Biotechnology, Dallas, TX, USA), Cytc (1:1000; Cell Signaling Technology, Danvers, MA, USA), Bax (1:100; Santa Cruz Biotechnology), Bcl-2 (1:200; Santa Cruz Biotechnology), caspase-9 (1:200; Santa Cruz Biotechnology), FAS (1:200; Santa Cruz Biotechnology), cleaved caspase-3 (1:1000; Cell Signaling Technology), or $\beta$-actin (1:1000; Cell Signaling Technology), and incubated at $4^{\circ} \mathrm{C}$ overnight. All membranes were followed by anti-rabbit/antimouse secondary antibodies $\left(1: 1000\right.$; Beyotime) at $37^{\circ} \mathrm{C}$ for 2 h. Quantity One (Version 4.5.2; Bio-Rad, Hercules, CA, USA) was used to determine the protein expression, which was recorded as the ratio of the target protein relative to $\beta$ actin [24].

2.4. Quantitative Real-Time PCR (qPCR) Analysis. qPCR was performed to detect the mRNA expression of a variety of signaling pathways, such as CaSR, CXCR-4, Cyt-c, and FAS, as previously described $[23,25]$. Total RNA was isolated from the conjunctive areas using TRIZOL Reagent (Invitrogen, Thermo Fisher Scientific, Waltham, MA, USA) and subjected to reverse transcription reactions with hexamer and M-MuLV reverse transcriptase (New England Biolabs, Ipswich, MA, USA). These cDNA products were used as the PCR templates. The primer sequences used in real-time 
qPCR were as follows: CaSR forward $5^{\prime}$-TGGCTCCCTGATCGGCTATACC- $3^{\prime}$, reverse $5^{\prime}$-GGGAAGGCTTGAAGAGGATAATGTA-3'; CXCR4 forward 5'-GCAATGGGTTGGTAATCCTG- $3^{\prime}$, reverse $5^{\prime}$-CCAGAAGGGGAGTGTGATGA-3'; Cyt-c forward 5'-CACAGATGCCAACAAGAACAA- $3^{\prime}$, reverse $5^{\prime}$-GTCTGCCCTTTCTCCCTTCT-3'; FAS forward $5^{\prime}$-GTCTTGGGGATTTGCCTACA- $3^{\prime}$, reverse $5^{\prime}$-GAACGCTACTGGGTTTGTCC- $3^{\prime}$; and GAPDH forward $5^{\prime}$-GACATGCCGCCTGGAGAAAC- $3^{\prime}$, reverse $5^{\prime}$ AGCCCAGGATGCCCTTTAGT-3'. PCR was performed using a real-time $\mathrm{qPCR}$ system $\left(\mathrm{SYBR}^{\circledR}\right.$ Premix Ex Taq ${ }^{\mathrm{TM}}$ II; TaKaRa, Tokyo, Japan), with 39 cycles of denaturation at $95^{\circ} \mathrm{C}$ for $30 \mathrm{~s}$, annealing at $60^{\circ} \mathrm{C}$ for $30 \mathrm{~s}$, and polymerization at $72^{\circ} \mathrm{C}$ for $30 \mathrm{~s}$. The relative gene expression levels were calculated according to $\Delta \mathrm{Ct}(\Delta \Delta \mathrm{Ct})$ method as follows: target amount $=2^{-\Delta \Delta \mathrm{Ct}}$ [26]. GAPDH was used as an internal control.

2.5. Immunohistochemical (IHC) Analysis and Neovascularization. IHC was used to detect the types of vital molecules expressed in tissues from conjunctive areas collected after $2 \mathrm{~h}$ or $7 \mathrm{~d}$ of reperfusion as previously described [17, 25, 27]. Briefly, $5 \mu \mathrm{m}$ thick paraffin sections were stained with antibodies to CD34 (1:250; Abcam, Cambridge, UK) and CaSR (1:200; Bioworld Technology). The microvessel density (MVD) in neovascularization was assessed by measuring the number of CD34-positive capillaries in 18 fields as described by Hollingsworth et al. [28].

2.6. Apoptosis Assay. An In Situ Cell Death Detection Kit (Roche, Basel, Switzerland) was utilized for quantitative detection of apoptotic cells by labeling DNA strand breaks (free $3^{\prime}-\mathrm{OH}$ terminal) at the single-cell level [29]. Briefly, $5 \mu \mathrm{m}$ thick paraffin sections were managed as in regular IHC, and then TUNEL reaction mixture (TdT-mediated dUTP$\mathrm{X}$ nick-end labeling, at $37^{\circ} \mathrm{C}$ for $60 \mathrm{~min}$ ), Converter-POD (at $37^{\circ} \mathrm{C}$ for $30 \mathrm{~min}$ ), and $\mathrm{DAB}$ (at room temperature for $10 \mathrm{~min}$ ) were sequentially added to the sections. The apoptotic ratio was calculated as the percentage of the number of TUNEL-positive cells relative to the total number of vascular endothelial cells [30].

2.7. Statistical Analysis. All data are expressed as the mean \pm standard deviation and were evaluated using SPSS (Version 19.0; IBM Corp., Armonk, NY, USA). Comparisons were examined using Tukey's method for one-way analysis of variance. A value of $P<0.05$ was considered statistically significant. The histograms were created by GraphPad Prism 5 (GraphPad Software, La Jolla, CA, USA), and the final figures were assembled by CorelDRAW(R) Graphics Suite X4 (Corel, Ottawa, Ontario, Canada).

\section{Results}

3.1. Evaluation of Free Flap Survival. The necrotic ratio (percentage of necrotic area relative to total flap surface area) was calculated by computer-aided planimetry to evaluate the free flap survival on postoperative day 7 . Five deciduous flaps were supplemented because of scratching by the rats. As shown in Figure 1(a), the necrotic sites were consistently located at the edge and distal end of each flap. The necrotic ratios in the five groups $\left(\mathrm{CaCl}_{2}, \mathrm{NPS} 2143+\mathrm{CaCl}_{2}, \mathrm{SDF}-\right.$ $1 \alpha+\mathrm{CaCl}_{2}, \mathrm{AMD} 3100+\mathrm{SDF}-1 \alpha+\mathrm{CaCl}_{2}$, and NS) were $14.16 \% \pm 0.36 \%, 5.49 \% \pm 0.62 \%, 4.87 \% \pm 0.24 \%, 7.00 \% \pm$ $0.09 \%$, and $9.92 \% \pm 0.41 \%$, respectively. The necrotic ratio in the $\mathrm{CaCl}_{2}$ group was significantly higher than those in the NS control group and other treatment groups, while the necrotic ratios in the NPS2143 $+\mathrm{CaCl}_{2}$ and SDF- $1 \alpha+\mathrm{CaCl}_{2}$ groups were significantly lower than that in the NS group (Figure 1).

3.2. Apoptosis Analysis. As shown in Figure 1(b), apoptotic cells were detected by TUNEL staining after $2 \mathrm{~h}$ or $7 \mathrm{~d}$ of reperfusion. The numbers of apoptotic cells in the $\mathrm{CaCl}_{2}$ group were remarkably higher than those in the other groups, while the apoptotic cells in the NPS2143 $+\mathrm{CaCl}_{2}$ and SDF-1 $\alpha$ $+\mathrm{CaCl}_{2}$ groups were notably decreased (Figure 1 ).

3.3. Immunohistochemical Analysis and Assessment of Neovascularization. The MVD was evaluated to assess the neovascularization of free flaps affected by I/R injury after $2 \mathrm{~h}$ or $7 \mathrm{~d}$ of reperfusion (Figure 2(a)). The mean MVDs for the five groups after $2 \mathrm{~h}$ of reperfusion were $3.00 \pm 0.81$, $9.14 \pm 1.57,9.29 \pm 1.98,5.57 \pm 1.27$, and $4.71 \pm 0.95$, while the mean MVDs for the five groups after $7 \mathrm{~d}$ of reperfusion were $4.57 \pm 0.98,11.29 \pm 2.56,11.43 \pm 2.51,7.71 \pm 1.80$, and $7.00 \pm 0.82$. These groups acquired the same tendency at two different points. The $\mathrm{CaCl}_{2}$ group showed the lowest MVD, while the NPS2143 $+\mathrm{CaCl}_{2}$ and SDF- $1 \alpha+\mathrm{CaCl}_{2}$ groups showed notably enhanced neovascularization compared with the control group (Figure 2).

As shown in Figure 2(b), CaSR was assessed by IHC staining. The mean optical densities of the five groups after $2 \mathrm{~h}$ of reperfusion following ischemia were $0.154 \pm 0.005$, $0.022 \pm 0.004,0.022 \pm 0.006,0.066 \pm 0.002$, and $0.084 \pm 0.002$, while the mean optical densities after $7 \mathrm{~d}$ of reperfusion were $0.129 \pm 0.009,0.026 \pm 0.007,0.023 \pm 0.003,0.060 \pm 0.004$, and $0.085 \pm 0.004$; that is, these groups also manifested the same trend. The $\mathrm{CaCl}_{2}$ group exhibited the highest expression of CaSR in vascular endothelial cells and partial blood cells, while the NPS2143 $+\mathrm{CaCl}_{2}$ and SDF- $1 \alpha+\mathrm{CaCl}_{2}$ groups showed the lowest CaSR expression compared with the NS control group (Figure 2).

3.4. Expressions of Various Proteins by Western Blot Analysis. The protein expression levels of p-CaSR, CXCR4, FAS, Cytc, caspase-9, cleaved caspase-3, Bax, and Bcl-2 were assessed by western blot analysis after $2 \mathrm{~h}$ or $7 \mathrm{~d}$ of reperfusion of free flaps. The expression levels of p-CaSR, FAS, Cyt-c, caspase9, cleaved caspase-3, and $\mathrm{Bax}$ were higher in the $\mathrm{CaCl}_{2}$ group than in all other groups, while these proteins showed significantly lower expression levels in the NPS2143 $+\mathrm{CaCl}_{2}$ and SDF- $1 \alpha+\mathrm{CaCl}_{2}$ groups. The expression level of $\mathrm{p}-\mathrm{CaSR}$ was significantly different after $2 \mathrm{~h}$ of reperfusion between the different treatment groups after I/R of free flaps; however, no significance difference was observed after $7 \mathrm{~d}$ of reperfusion among Groups B, C, D, and E after I/R. The expression levels 


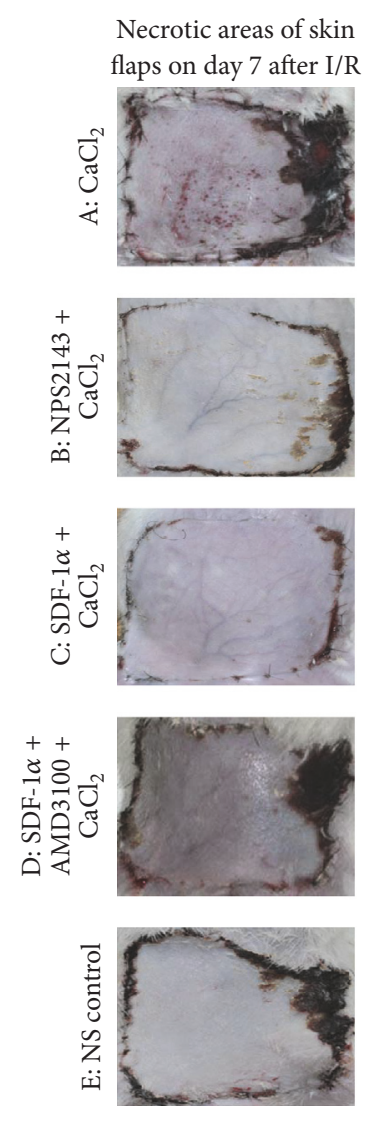

(a)

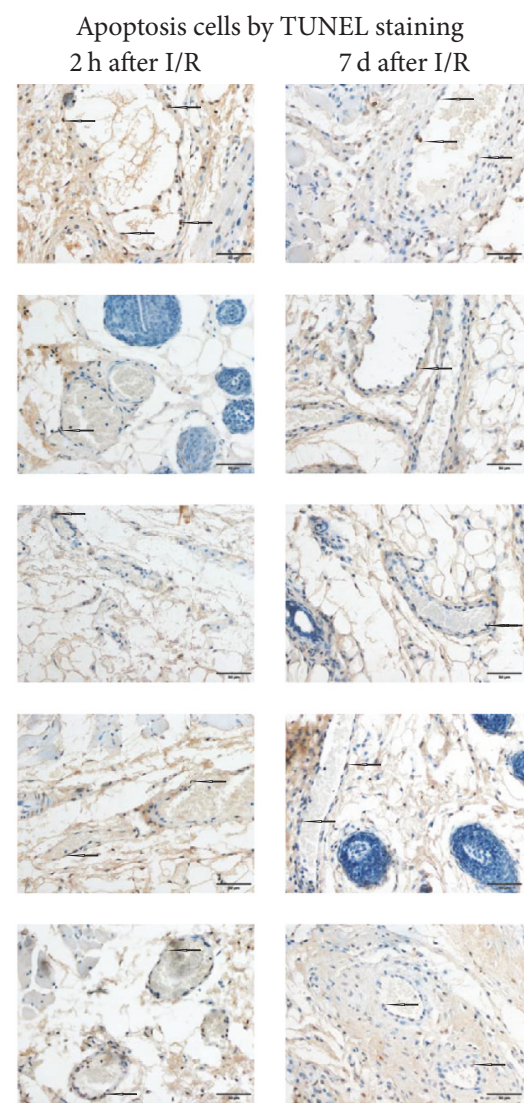

(b)
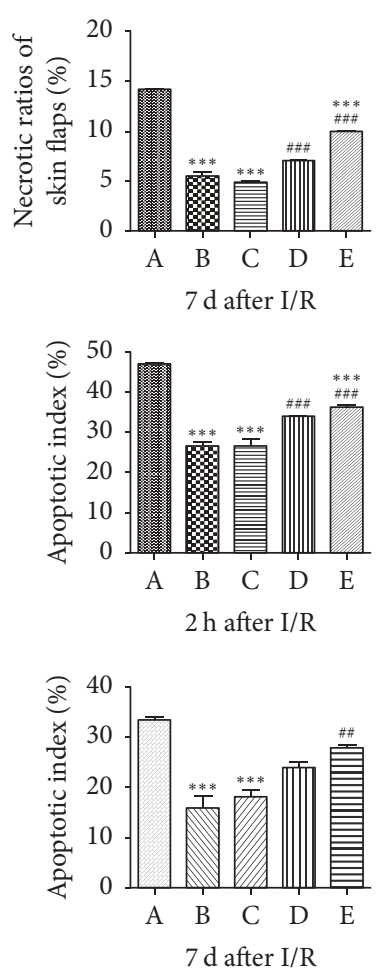

FIgURE 1: (a) Free flap survival status on day 7 after ischemia/reperfusion (I/R). The necrotic ratio in the $\mathrm{CaCl}_{2}$ group was significantly higher than that of the other groups, while the necrotic ratios in the NPS2143 $+\mathrm{CaCl}_{2}$ and SDF-1 $\alpha+\mathrm{CaCl}_{2}$ groups were significantly lower than

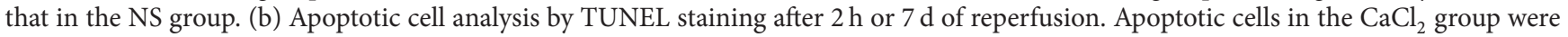
remarkably increased, while apoptotic cells in the NPS2143 $+\mathrm{CaCl}_{2}$ and SDF- $1 \alpha+\mathrm{CaCl}_{2}$ groups were notably decreased compared with the other groups. ${ }^{* * *} P<0.001$ versus $\mathrm{CaCl}_{2}$ group, ${ }^{\# \# \#} \mathrm{P}<0.001$ versus $\mathrm{SDF}-1 \alpha+\mathrm{CaCl}_{2}$ group, ${ }^{\# \#} \mathrm{P}<0.01$ versus $\mathrm{SDF}-1 \alpha+\mathrm{CaCl}{ }_{2}$ group.

of FAS and Cyt-c showed the same tendency both after $2 \mathrm{~h}$ and $7 \mathrm{~d}$ of reperfusion of free flaps. The protective protein CXCR4 showed the strongest expression, while the proapoptotic protein caspase-9 displayed the weakest expression with time in the SDF- $1 \alpha+\mathrm{CaCl}_{2}$ group. Unlike the other proapoptotic proteins, Bcl-2/Bax showed higher expression in the SDF- $1 \alpha$ $+\mathrm{CaCl}_{2}$ group than in all other groups (Figure 3).

3.5. mRNA Expressions by $q P C R$ Analysis. The mRNA expression levels of CaSR, CXCR4, FAS, and Cyt-c were detected by qPCR analysis after $2 \mathrm{~h}$ or $7 \mathrm{~d}$ of reperfusion of free flaps. The expression level of CaSR was higher in the $\mathrm{CaCl}_{2}$ group than those in the NPS2143 $+\mathrm{CaCl}_{2}$ and SDF$1 \alpha+\mathrm{CaCl}_{2}$ groups at both time points. The expression level of CXCR4 in the SDF- $1 \alpha+\mathrm{CaCl}_{2}$ group was significantly higher than that in the $\mathrm{CaCl}_{2}$ group and control group after I/R. Furthermore, the expression levels of FAS and Cyt-c were higher in the $\mathrm{CaCl}_{2}$ group than those in all other groups after $2 \mathrm{~h}$ or $7 \mathrm{~d}$ of reperfusion of free flaps, showing a consistent tendency with the expression levels of CaSR and western blot analysis (Figure 4).

\section{Discussion}

In this study, the authors investigated whether CaSR is functionally expressed in the vascular endothelial cells of free flaps and plays a detrimental role in I/R injury of free flaps. They also assessed whether administration of SDF- $1 \alpha$ can protect free flaps from I/R injury and alleviate CaSR partial (control group) or extensive (such as $\mathrm{CaCl}_{2}$ group) activation-mediated $\mathrm{I} / \mathrm{R}$ injury in rat free flaps.

According to the results from the $\mathrm{CaCl}_{2}$ (a CaSR agonist) group, NPS2143 (a CaSR inhibitor) $+\mathrm{CaCl}_{2}$ group, SDF- $1 \alpha$ (a CXCR4 agonist) $+\mathrm{CaCl}_{2}$ group, $\mathrm{AMD} 3100$ (a CXCR4 antagonist) $+\mathrm{SDF}-1 \alpha+\mathrm{CaCl}_{2}$ group, and NS control group, $\mathrm{p}$-CaSR and CaSR were extensively expressed in the vascular endothelial cells of free flaps (Figures 2 and 3). Additionally, the level of $\mathrm{p}$-CaSR expression was closely associated with the level of I/R injury.

Functional studies have demonstrated that activation of CaSR by I/R could lead to myocardial I/R injury by activating cell apoptosis [6,31,32] and "calcium overload" because $\mathrm{CaCl}_{2}$ is a typical agonist of CaSR [7]; however, NPS2143 is known to inhibit CaSR [33]. Consistent with other studies, the 


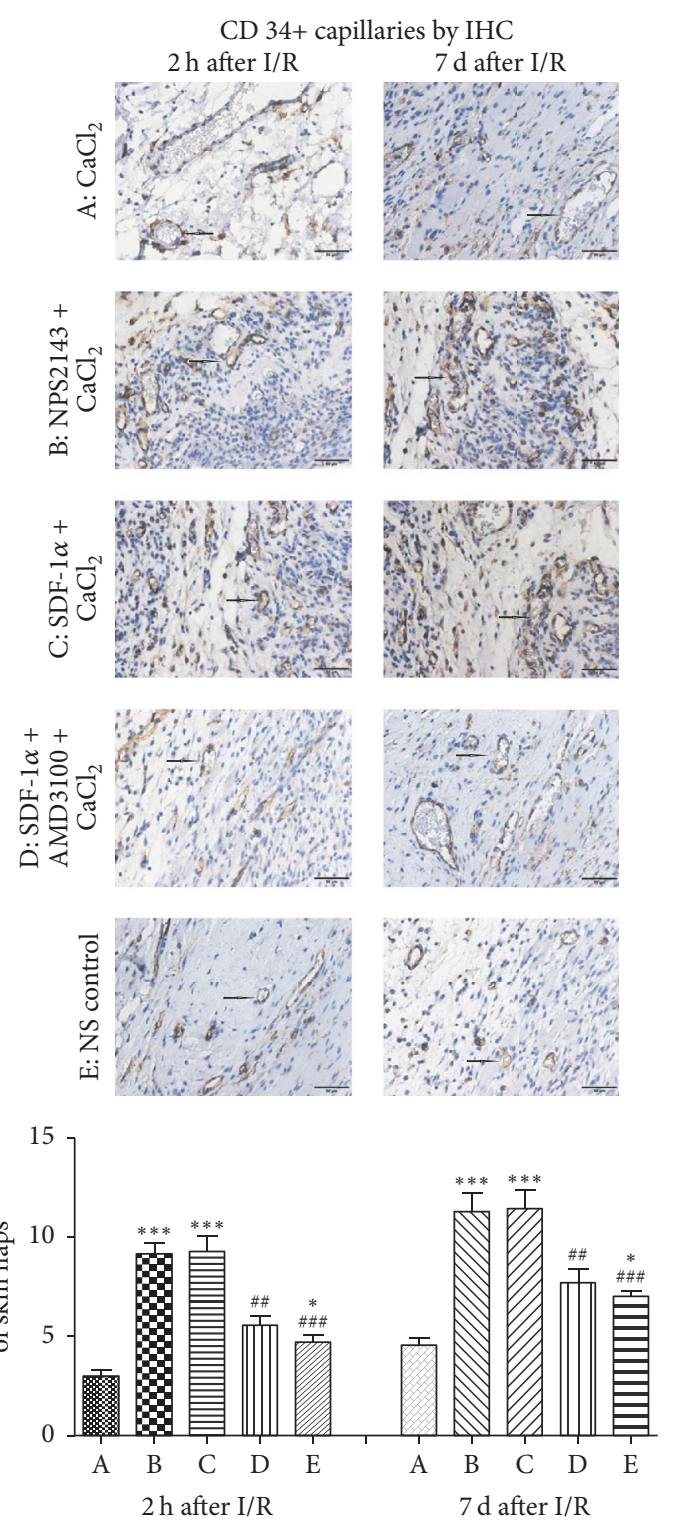

(a)
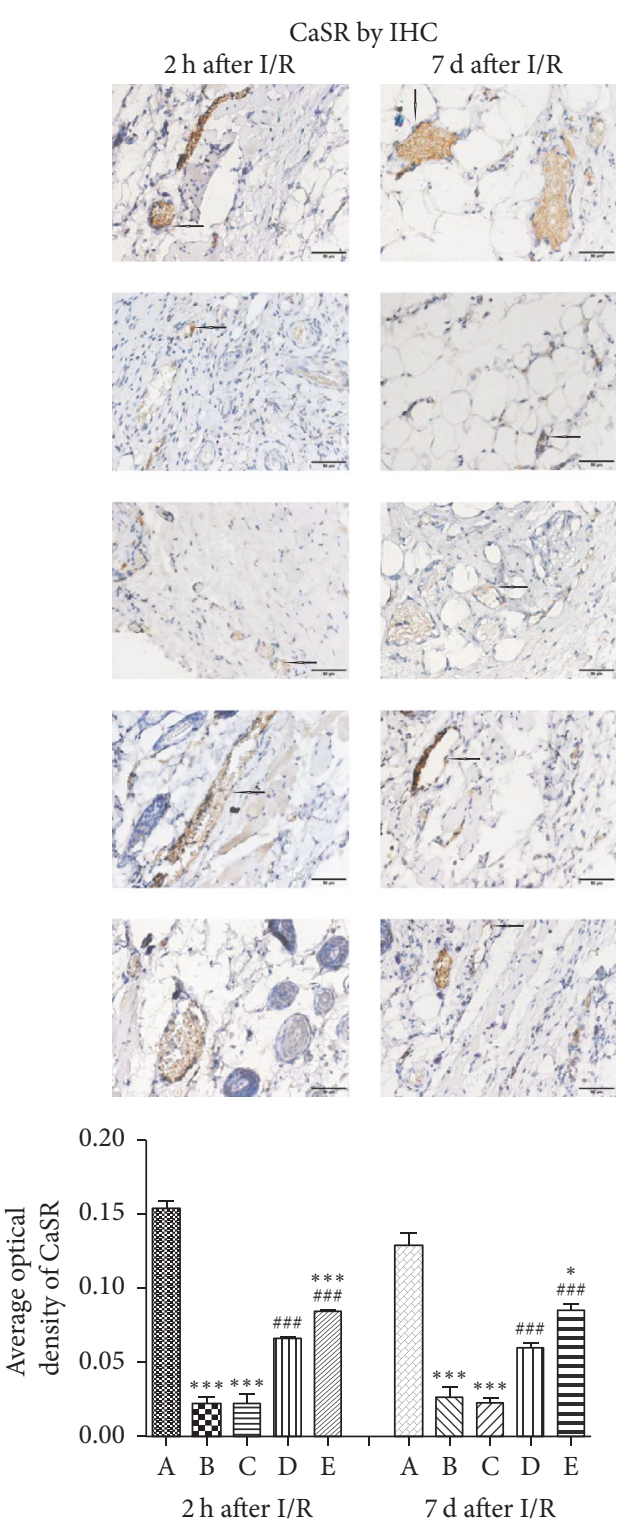

(b)

Figure 2: (a) MVD in neovascularization stained by CD34-positive capillaries was examined using IHC staining after $2 \mathrm{~h}$ or $7 \mathrm{~d}$ of reperfusion. The $\mathrm{CaCl}_{2}$ group yielded the lowest MVD, while the NPS2143 $+\mathrm{CaCl}_{2}$ and SDF- $1 \alpha+\mathrm{CaCl}_{2}$ groups exhibited notably enhanced neovascularization compared with the control group. (b) CaSR by IHC staining after $2 \mathrm{~h}$ or $7 \mathrm{~d}$ of reperfusion. The $\mathrm{CaCl}_{2}$ group exhibited the highest expression of CaSR in vascular endothelial cells and partial blood cells, while the expressions levels of CaSR in the $\mathrm{NPS} 2143+\mathrm{CaCl}_{2}$ and SDF- $1 \alpha+\mathrm{CaCl}_{2}$ groups were lower than those in the NS control group. ${ }^{* * *} P<0.001$ versus $\mathrm{CaCl}_{2}$ group, ${ }^{*} \mathrm{P}<0.05$ versus CaCl 2 group, ${ }^{\# \# \#} P<0.001$ versus SDF- $1 \alpha+\mathrm{CaCl}_{2}$ group, ${ }^{\# \#} P<0.01$ versus SDF- $1 \alpha+\mathrm{CaCl}_{2}$ group.

authors demonstrated that a high expression level of $\mathrm{p}$-CaSR indicates severe I/R injury of free flaps, while a low $\mathrm{p}$-CaSR expression level indicates mild I/R injury (Figures 1-4). The $\mathrm{CaCl}_{2}$ group exhibited significantly more flap necrosis, which was consistent with the higher number of apoptotic cells detected by the TUNEL staining (Figure 1); lower MVD and more CaSR detected by IHC staining (Figure 2); the highest proapoptotic protein expressions of p-CaSR, cleaved caspase3 , and caspase- 9 detected by western blot analysis (Figure 3); and the highest mRNA expression of CaSR detected by qPCR analysis (Figure 4). However, the NPS2143 $+\mathrm{CaCl}_{2}$ group exhibited less flap necrosis, which was consistent with fewer apoptotic cells (Figure 1), a high MVD, less CaSR (Figure 2), and low proapoptotic protein expressions of $\mathrm{p}$-CaSR, cleaved caspase- 3 and caspase-9 (Figure 3 ) after $2 \mathrm{~h}$ of reperfusion but not always after $7 \mathrm{~d}$ of reperfusion of free flaps. These results imply that the potential hypoxic signaling pathways that stimulate revascularization were downregulated and that the revascularization process might cease after 7 days [34]. These results suggest that extensive CaSR activation 

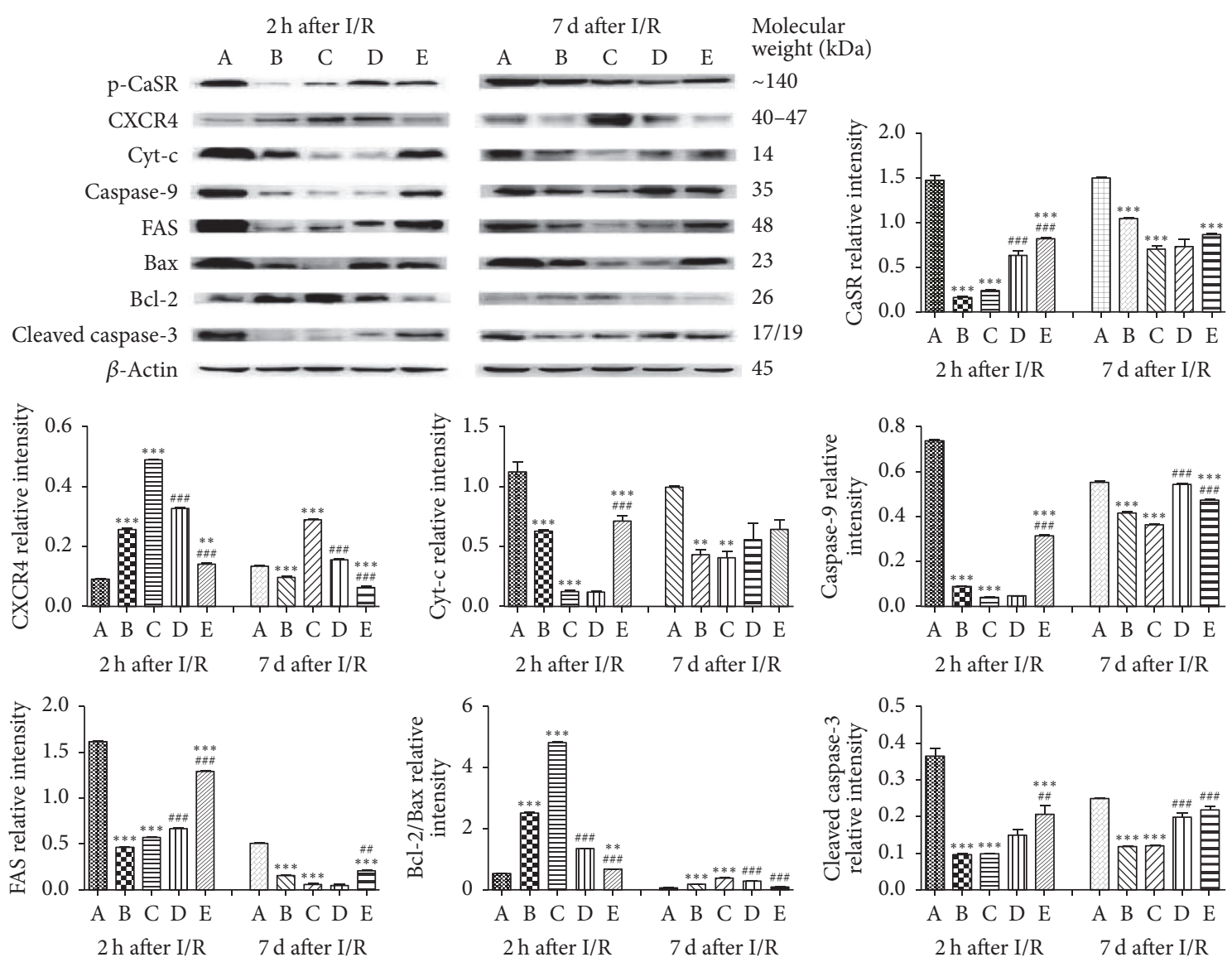

Figure 3: The protein expression levels of p-CaSR, CXCR4, FAS, Cyt-c, caspase-9, Bax, Bcl-2, and cleaved caspase-3 were assessed by western blot analysis after $2 \mathrm{~h}$ or $7 \mathrm{~d}$ of reperfusion. The expression levels of p-CaSR, FAS, Cyt-c, caspase- 9 , and Bax were highest in the CaCl ${ }_{2}$ group, while the expression levels of these proteins were significantly lower in the NPS2143 $+\mathrm{CaCl}_{2}$ and SDF- $1 \alpha+\mathrm{CaCl}_{2}$ groups. The expression levels of p-CaSR showed a significant difference at hour 2 but not on day 7 after I/R of free flaps. The expression level of CXCR4 was the strongest while that of caspase- 9 was the weakest in the SDF- $1 \alpha+\mathrm{CaCl}_{2}$ group over time ${ }^{* * *} P<0.001$ versus $\mathrm{CaCl}_{2}$ group, ${ }^{* *} P<0.01$ versus $\mathrm{CaCl}_{2}$ group, ${ }^{\# \#} P<0.001$ versus $\mathrm{SDF}-1 \alpha+\mathrm{CaCl}_{2}$ group, ${ }^{\# \#} P<0.01$ versus $\mathrm{SDF}-1 \alpha+\mathrm{CaCl}_{2}$ group.

plays a detrimental role in I/R injury of free flaps by promoting caspase-3/caspase-9-dominated cell apoptosis and that extensive activation of CaSR could be induced by the administration of $\mathrm{CaCl}_{2}$ while this proapoptotic effect could be neutralized by NPS2143.

A variety of approaches or reagents have been administered to exert preventive effects against necrosis of free flaps or skin grafts $[1,17,35-37]$. According to previous studies, SDF-1 plays a critical and unique role in angiogenesis and vasculogenesis by enhancing MVD in neovascularization $[15,17]$. AMD3100 functions as an antagonist of CXCR4 [16]. No relationship has previously been observed between CaSR and the SDF-1 $\alpha /$ CXCR4 biological axis. However, the present study initially revealed that the SDF-1 $\alpha /$ CXCR 4 axis was intimately associated with CaSR activation in I/R injury of free flaps. The SDF- $1 \alpha+\mathrm{CaCl}_{2}$ group exhibited the least flap necrosis, which was consistent with fewer apoptotic cells (Figure 1), high MVD, less CaSR (Figure 2), and low proapoptotic protein expression of $\mathrm{p}$-CaSR, cleaved caspase3 and caspase-9 (Figure 3) after $2 \mathrm{~h}$ of reperfusion but not necessarily after $7 \mathrm{~d}$ of reperfusion of free flaps, revealing a tendency very similar to that in the NPS2143 (i.e., a CaSR inhibitor) $+\mathrm{CaCl}_{2}$ group. The AMD3100 $+\mathrm{SDF}-1 \alpha+\mathrm{CaCl}_{2}$ group displayed an almost opposite tendency compared with the SDF- $1 \alpha+\mathrm{CaCl}_{2}$ group. These results suggest that the SDF$1 \alpha /$ CXCR 4 axis activated by SDF- $1 \alpha$ might protect free flaps from I/R injury by inhibiting caspase-3/caspase-9-induced cell apoptosis and that the activation of SDF- $1 \alpha /$ CXCR 4 axis and this antiapoptotic effect could almost be neutralized by AMD3100

These results provide insight into the activation of the SDF-1 $\alpha$ /CXCR4 axis, showing that this axis could function as a CaSR inhibitor to significantly alleviate the extensive CaSR activation-mediated I/R injury of free flaps through the inhibition of cell apoptosis by reducing the proapoptotic protein expressions of FAS, Bax, Cyt-c, caspase-9, and cleaved caspase- 3 and increasing the antiapoptotic protein expression of Bcl-2 (Figure 5). Interestingly, these results also suggest that initiation of the SDF-1 $\alpha /$ CXCR 4 axis might neutralize the CaSR partial or extensive activation to alleviate the I/R injury of free flaps by enhancement of MVD in neovascularization through the abundant expression of CD34. 

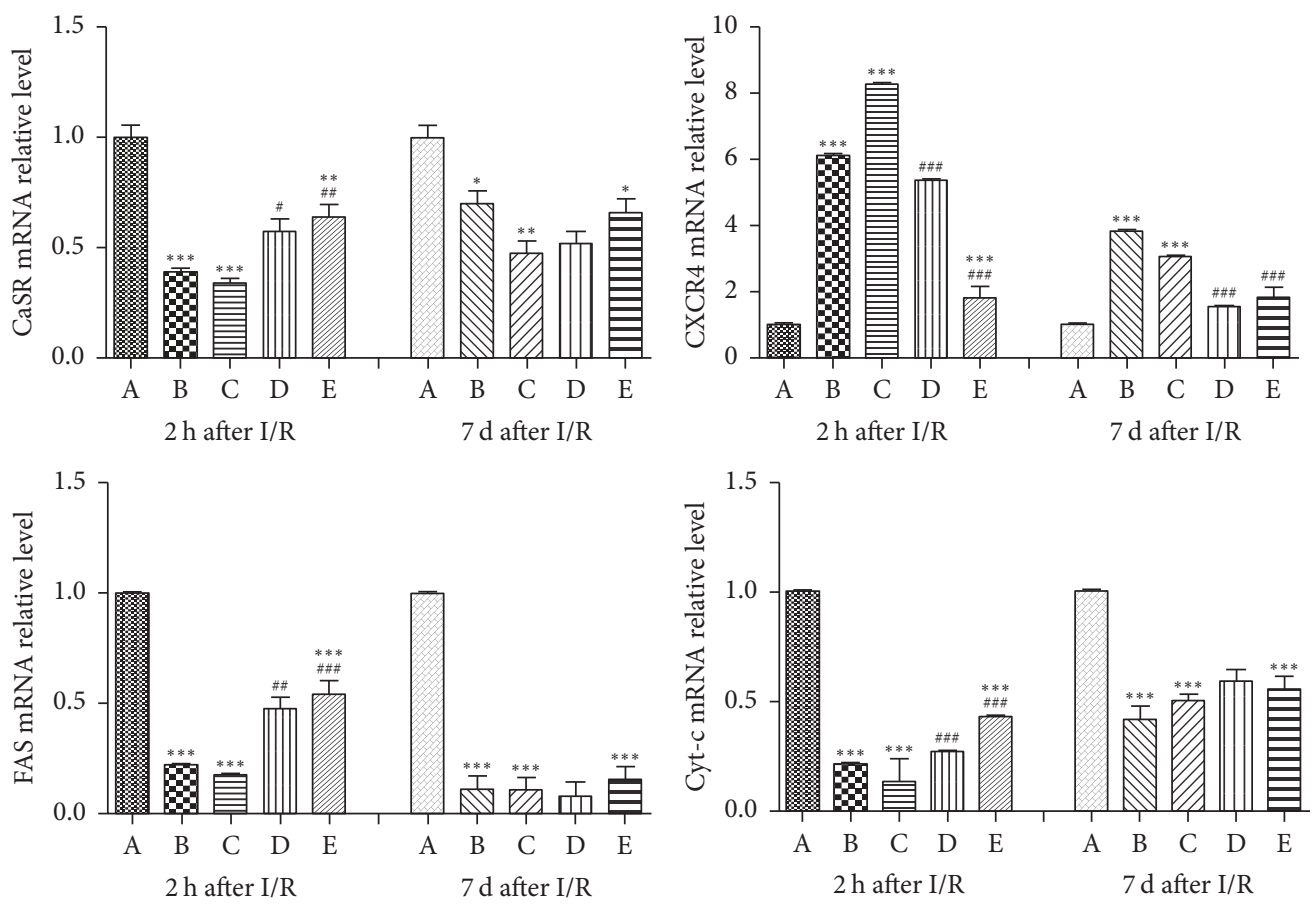

FIgURE 4: The mRNA expression levels of CaSR, CXCR4, FAS, and Cyt-c were detected by qPCR analysis after $2 \mathrm{~h}$ or $7 \mathrm{~d}$ of reperfusion of free flaps. The expression levels of CaSR, FAS, and Cyt-c were higher in the $\mathrm{CaCl}_{2}$ group than those in all other groups at both time points. The expression level of CXCR4 in the SDF- $1 \alpha+\mathrm{CaCl}_{2}$ group was significantly higher than that in the $\mathrm{CaCl}_{2}$ and control groups after I/R of free flaps. ${ }^{* * *} P<0.001$ versus $\mathrm{CaCl}_{2}$ group, ${ }^{* *} P<0.01$ versus $\mathrm{CaCl}_{2}$ group, ${ }^{*} P<0.05$ versus $\mathrm{CaCl}_{2}$ group, ${ }^{\# \# \#} P<0.001$ versus $\mathrm{SDF}-1 \alpha+$ $\mathrm{CaCl}_{2}$ group, ${ }^{\# \#} \mathrm{P}<0.01$ versus SDF- $1 \alpha+\mathrm{CaCl}_{2}$ group, ${ }^{\#} P<0.05$ versus $\mathrm{SDF}-1 \alpha+\mathrm{CaCl}_{2}$ group.

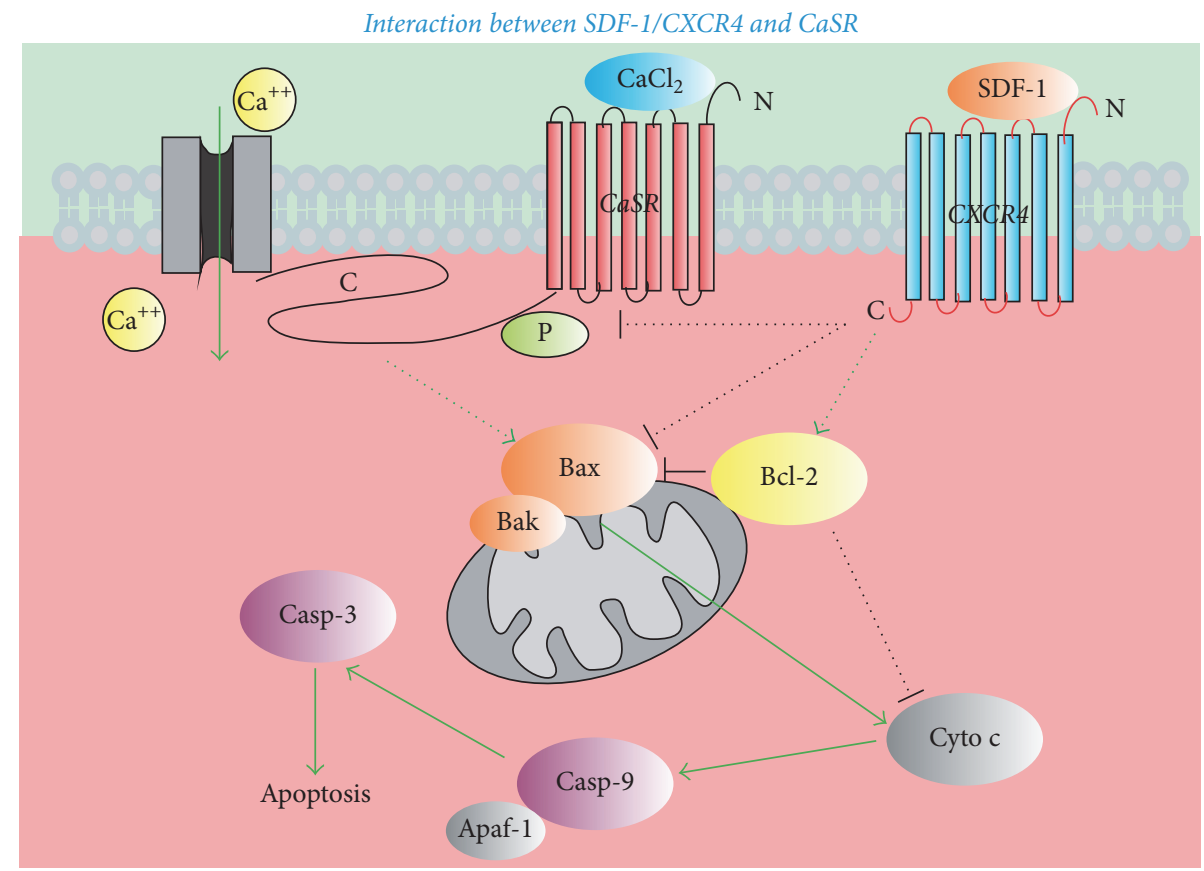

FIGURE 5: Schematic diagram of the interaction between SDF-1 $\alpha$ /CXCR4 and CaSR. Activation of CaSR increased the expression of Bax, then Cyt-c, caspase-9, and cleaved caspase-3; it finally caused cell apoptosis. Activation of the SDF-1 $\alpha /$ CXCR4 axis alleviated this process as Bcl-2. 
In summary, extensive p-CaSR/CaSR expression was initially demonstrated in vascular endothelial cells of free flaps affected by I/R injury, and inhibition of $\mathrm{p}$-CaSR might become a novel therapeutic target for free flaps affected by $\mathrm{I} / \mathrm{R}$ injury. The authors conclude that activation of the SDF-1 $\alpha /$ CXCR 4 axis and NPS2143 could protect free flaps from I/R injury and counteract partial or extensive CaSR activation-mediated necrosis of free flaps by inhibiting extensive caspase-3/caspase-9 expression-induced cell apoptosis and enhancement of MVD in the neovascularization of free flaps. However, the underlying mechanism of the interactions between the SDF-1 $\alpha /$ CXCR 4 axis and CaSR or other G protein-coupled receptors remain to be elucidated.

\section{Conflicts of Interest}

The authors declare that there are no conflicts of interest regarding the publication of this article.

\section{Authors' Contributions}

Fu-Gui Zhang and Ping Ji conducted study conception and design. Li Song, Li-Na Gao, Jun Wang, Swosti Thapa, Yong Li, Xue-Rong Xiang, and Xiao-Bo Zhong assisted in data acquisition or analysis/interpretation. Hong-Wei Zhao helped in drafting or revision of article. Fu-Gui Zhang and Ping Ji gave final approval of the version to be submitted.

\section{Acknowledgments}

The authors appreciate the help of Tong-Chuan He, Hue H. Luu, and Rex C. Haydon from the University of Chicago Medical Center, USA, and they express gratitude to HongMei Zhang, En-Yi Huang, Wen-Ping Luo, and Yan Zhang from China for facilitating collaboration. They also extend their thanks to En-Lai Shi, Yu-Meng Huang, Xiao-Zhu Yang, Yan Qiu, Chao Wang, Peng-Fei Zhou, Ping Liu, Lin Zeng, Xian Li, Qi-Ming Wang, Si-Hai Zou, Lu-Ying Zhu, and Qi $\mathrm{Lu}$ from China for their excellent technical assistance. Finally, they thank Angela Morben, DVM, ELS, from Liwen Bianji, Edanz Editing China, for editing the English text of a draft of this manuscript. This study was sponsored by the National Natural Science Foundation of China (no. 81400493), the Program of Chongqing Science \& Technology Commission (no. cstc2015shmszx10008), the Chongqing Yubei District Commission on Science \& Technology (no. 2015-\#01), the Project Supported by Program for Innovation Team Building at Institutions of Higher Education in Chongqing in 2016, and the Project Supported by Chongqing Municipal Key Laboratory of Oral Biomedical Engineering of Higher Education.

\section{Supplementary Materials}

Supplemental Figure 1 A 3-h period of flap ischemia was elected among different time points (i.e., hours 1, 2, 3, and 4) because of the highest expression of $\mathrm{p}$-CaSR protein. $* * * P$ $<0.001$ versus 3 -h of ischemia. (Supplementary Materials)

\section{References}

[1] P. Lubiatowski, C. K. Goldman, R. Gurunluoglu, K. Carnevale, and M. Siemionow, "Enhancement of epigastric skin flap survival by adenovirus-mediated VEGF gene therapy," Plastic and Reconstructive Surgery, vol. 109, no. 6, pp. 1986-1993, 2002.

[2] F. Sofiadellis, D. Liu, A. Webb, K. MacGill, W. M. Rozen, and M. W. Ashton, "Fasciocutaneous free flaps are more reliable than muscle free flaps in lower limb trauma reconstruction: experience in a single trauma center," Journal of Reconstructive Microsurgery, vol. 28, no. 5, pp. 333-339, 2012.

[3] W. Z. Wang, R. C. Baynosa, and W. A. Zamboni, "Update on ischemia-reperfusion injury for the plastic surgeon: 2011," Plastic and Reconstructive Surgery, vol. 128, no. 6, pp. 685e-692e, 2011.

[4] E. M. Brown, G. Gamba, D. Riccardi et al., "Cloning and characterization of an extracellular $\mathrm{Ca}^{2+}$-sensing receptor from bovine parathyroid," Nature, vol. 366, no. 6455, pp. 575-580, 1993.

[5] W.-J. Xing, F.-J. Kong, G.-W. Li et al., "Calcium-sensing receptors induce apoptosis during simulated ischaemia-reperfusion in Buffalo rat liver cells," Clinical and Experimental Pharmacology and Physiology, vol. 38, no. 9, pp. 605-612, 2011.

[6] Y. Zhen, C. Ding, J. Sun, Y. Wang, S. Li et al., "Activation of the calcium-sensing receptor promotes apoptosis by modulating the JNK/p38 MAPK pathway in focal cerebral ischemia-reperfusion in mice," American Journal of Translational Research, vol. 8, pp. 911-921, 2016.

[7] R. Wang, C. Xu, W. Zhao et al., "Calcium and polyamine regulated calcium-sensing receptors in cardiac tissues," European Journal of Biochemistry, vol. 270, no. 12, pp. 2680-2688, 2003.

[8] S. Dong, Z. Teng, F.-H. Lu et al., "Post-conditioning protects cardiomyocytes from apoptosis via $\mathrm{PKC}_{\varepsilon}$-interacting with calcium-sensing receptors to inhibit endo(sarco)plasmic reticulum-mitochondria crosstalk," Molecular and Cellular Biochemistry, vol. 341, no. 1-2, pp. 195-206, 2010.

[9] G.-W. Li, Q.-S. Wang, J.-H. Hao et al., “The functional expression of extracellular calcium-sensing receptor in rat pulmonary artery smooth muscle cells," Journal of Biomedical Science, vol. 18 , no. 1, article no. 16, 2011.

[10] M. Bonomini, A. Giardinelli, C. Morabito et al., "Calcimimetic r-568 and its enantiomer s-568 increase nitric oxide release in human endothelial cells," PLoS ONE, vol. 7, no. 1, Article ID e30682, 2012.

[11] A. H. Weston, M. Absi, D. T. Ward et al., "Evidence in favor of a calcium-sensing receptor in arterial endothelial cells: studies with calindol and Calhex 231," Circulation Research, vol. 97, no. 4, pp. 391-398, 2005.

[12] H. Z. E. Greenberg, J. Shi, K. S. Jahan et al., "Stimulation of calcium-sensing receptors induces endothelium-dependent vasorelaxations via nitric oxide production and activation of IKCa channels," Vascular Pharmacology, vol. 80, pp. 75-84, 2016.

[13] T. Nagasawa, H. Kikutani, and T. Kishimoto, "Molecular cloning and structure of a pre-B-cell growth-stimulating factor," Proceedings of the National Academy of Sciences, vol. 91, no. 6, pp. 2305-2309, 1994.

[14] O. Salvucci, L. Yao, S. Villalba, A. Sajewicz, S. Pittaluga, and G. Tosato, "Regulation of endothelial cell branching morphogenesis by endogenous chemokine stromal-derived factor-1," Blood, vol. 99, no. 8, pp. 2703-2711, 2002. 
[15] X. Liu, F. Liang, J. Yang et al., "Effects of stromal cell derived factor-1 and CXCR 4 on the promotion of neovascularization by hyperbaric oxygen treatment in skin flaps," Molecular Medicine Reports, vol. 8, no. 4, pp. 1118-1124, 2013.

[16] S. Dai, F. Yuan, J. Mu et al., "Chronic AMD3100 antagonism of SDF-1 $\alpha$-CXCR4 exacerbates cardiac dysfunction and remodeling after myocardial infarction," Journal of Molecular and Cellular Cardiology, vol. 49, no. 4, pp. 587-597, 2010.

[17] F.-G. Zhang, Y. Yao, Y. Feng, C.-G. Hua, and X.-F. Tang, "Mesenchymal stem cells transduced by stromal cell-derived factor-1 $\alpha$ augment ischemic free flaps' survival," Annals of Plastic Surgery, vol. 66, no. 1, pp. 92-97, 2011.

[18] X. Hu, S. Dai, W.-J. Wu et al., "Stromal cell-derived factor$1 \alpha$ confers protection against myocardial ischemia/reperfusion injury: role of the cardiac stromal cell-derived factor- $1 \alpha$-CXCR 4 axis," Circulation, vol. 116, no. 6, pp. 654-663, 2007.

[19] Y. Yao, C. Hua, X. Tang, Y. Wang, F. Zhang, and Z. Xiang, "Angiogenesis and osteogenesis of non-vascularised autogenous bone graft with arterial pedicle implantation," Journal of Plastic, Reconstructive and Aesthetic Surgery, vol. 63, no. 3, pp. 467-473, 2010.

[20] Y.-D. Xiao, Y.-Q. Liu, J.-L. Li et al., "Hyperbaric oxygen preconditioning inhibits skin flap apoptosis in a rat ischemiareperfusion model," Journal of Surgical Research, vol. 199, no. 2, pp. 732-739, 2015.

[21] X.-Y. Wang, Y. Chen, X.-J. Tang, L.-H. Jiang, and P. Ji, “AMD3100 attenuates matrix metalloprotease- 3 and -9 expressions and prevents cartilage degradation in a monosodium iodo-acetateinduced rat model of temporomandibular osteoarthritis," Journal of Oral and Maxillofacial Surgery, vol. 74, no. 5, pp. 927.e1927.e13, 2016.

[22] Y. H. Tang, L. A. Pennington, J. W. Scordino, J. S. Alexander, and T. Lian, "Dynamics of early stem cell recruitment in skin flaps subjected to ischemia reperfusion injury," Pathophysiology, vol. 23, no. 3, pp. 221-228, 2016.

[23] Y. Li, E. R. Wagner, Z. Yan et al., "The calcium-binding protein S100A6 accelerates human osteosarcoma growth by promoting cell proliferation and inhibiting osteogenic differentiation," Cellular Physiology and Biochemistry, vol. 37, no. 6, pp. 23752392, 2015.

[24] J. Guo, H. Li, W. Zhang et al., "Increased expression of calciumsensing receptors induced by ox-LDL amplifies apoptosis of cardiomyocytes during simulated ischaemia-reperfusion," Clinical and Experimental Pharmacology and Physiology, vol. 37, no. 3, pp. e128-e135, 2010.

[25] Y. Deng, J. Zhang, Z. Wang et al., "Antibiotic monensin synergizes with EGFR inhibitors and oxaliplatin to suppress the proliferation of human ovarian cancer cells," Scientific Reports, vol. 5, Article ID 17523, 2015.

[26] S. U. Eisenhardt, Y. Schmidt, G. Karaxha et al., "Monitoring molecular changes induced by ischemia/reperfusion in human free muscle flap tissue samples," Annals of Plastic Surgery, vol. 68, no. 2, pp. 202-208, 2012.

[27] F. Zhang, Y. Li, H. Zhang et al., "Anthelmintic mebendazole enhances cisplatin's effect on suppressing cell proliferation and promotes differentiation of head and neck squamous cell carcinoma (HNSCC)," Oncotarget, vol. 8, no. 8, pp. 1296812982, 2017.

[28] H. C. Hollingsworth, E. C. Kohn, S. M. Steinberg, M. L. Rothenberg, and M. J. Merino, "Tumor angiogenesis in advanced stage ovarian carcinoma," American Journal of Pathology, vol. 147, no. 1, pp. 33-41, 1995.
[29] L. Galluzzi, S. A. Aaronson, J. Abrams, E. S. Alnemri, D. W. Andrews et al., "Guidelines for the use and interpretation of assays for monitoring cell death in higher eukaryotes," Cell Death \& Differentiation, vol. 16, pp. 1093-1107, 2009.

[30] K. Song, M. Zhang, J. Hu et al., "Methane-rich saline attenuates ischemia/reperfusion injury of abdominal skin flaps in rats via regulating apoptosis level," BMC Surgery, vol. 15, no. 1, article no. 92, 2015.

[31] L. Yan, T.-B. Zhu, L.-S. Wang et al., "Inhibitory effect of hepatocyte growth factor on cardiomyocytes apoptosis is partly related to reduced calcium sensing receptor expression during a model of simulated ischemia/reperfusion," Molecular Biology Reports, vol. 38, no. 4, pp. 2695-2701, 2011.

[32] H. Zheng, J. Liu, C. Liu et al., "Calcium-sensing receptor activating phosphorylation of PKC $\delta$ translocation on mitochondria to induce cardiomyocyte apoptosis during ischemia/reperfusion," Molecular and Cellular Biochemistry, vol. 358, no. 1-2, pp. 335343, 2011.

[33] K. Koori, H. Maeda, S. Fujii et al., "The roles of calcium-sensing receptor and calcium channel in osteogenic differentiation of undifferentiated periodontal ligament cells," Cell and Tissue Research, vol. 357, no. 3, pp. 707-718, 2014.

[34] J. M. Capla, D. J. Ceradini, O. M. Tepper et al., "Skin graft vascularization involves precisely regulated regression and replacement of endothelial cells through both angiogenesis and vasculogenesis," Plastic and Reconstructive Surgery, vol. 117, no. 3, pp. 836-844, 2006.

[35] M. Nowacki, K. Pietkun, A. Jundziłł et al., "Use of adiposederived stem cells to support topical skin adhesive for wound closure: a preliminary report from animal in vivo study," BioMed Research International, vol. 2016, Article ID 2505601, 10 pages, 2016.

[36] J. Wang, H. Hao, H. Huang, D. Chen, Y. Han, and W. Han, "The effect of adipose-derived stem cells on full-thickness skin grafts," BioMed Research International, vol. 2016, Article ID 1464725, 10 pages, 2016.

[37] Y.-S. Tzeng, S.-C. Deng, C.-H. Wang, J.-C. Tsai, T.-M. Chen, and T. Burnouf, "Treatment of nonhealing diabetic lower extremity ulcers with skin graft and autologous platelet gel: a case series," BioMed Research International, vol. 2013, Article ID 837620, 9 pages, 2013. 


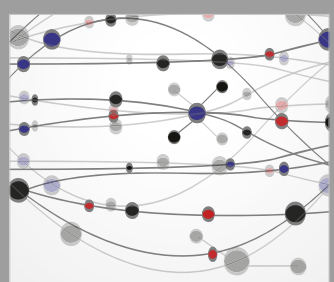

The Scientific World Journal
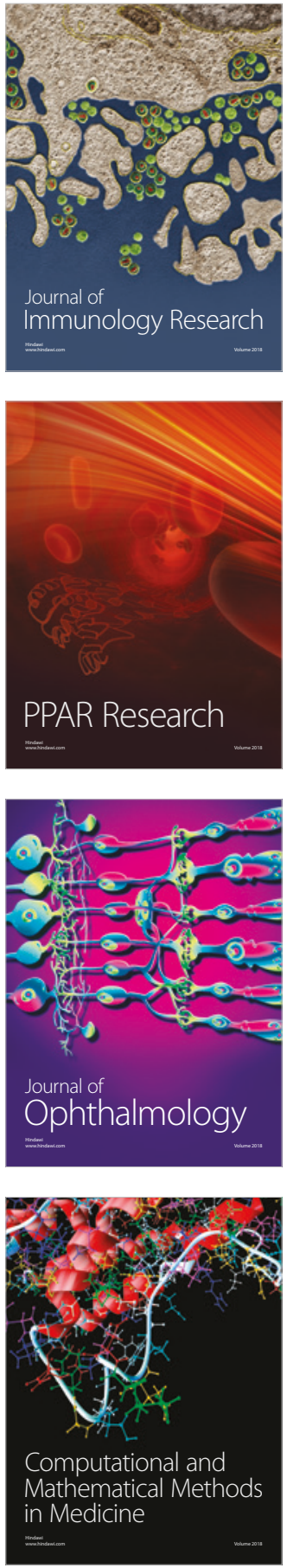

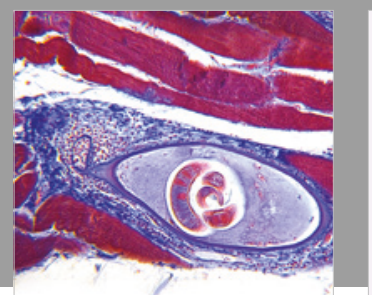

Gastroenterology Research and Practice

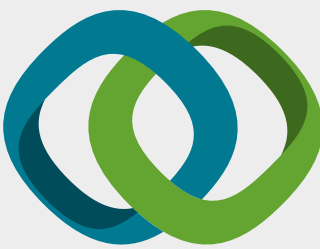

\section{Hindawi}

Submit your manuscripts at

www.hindawi.com
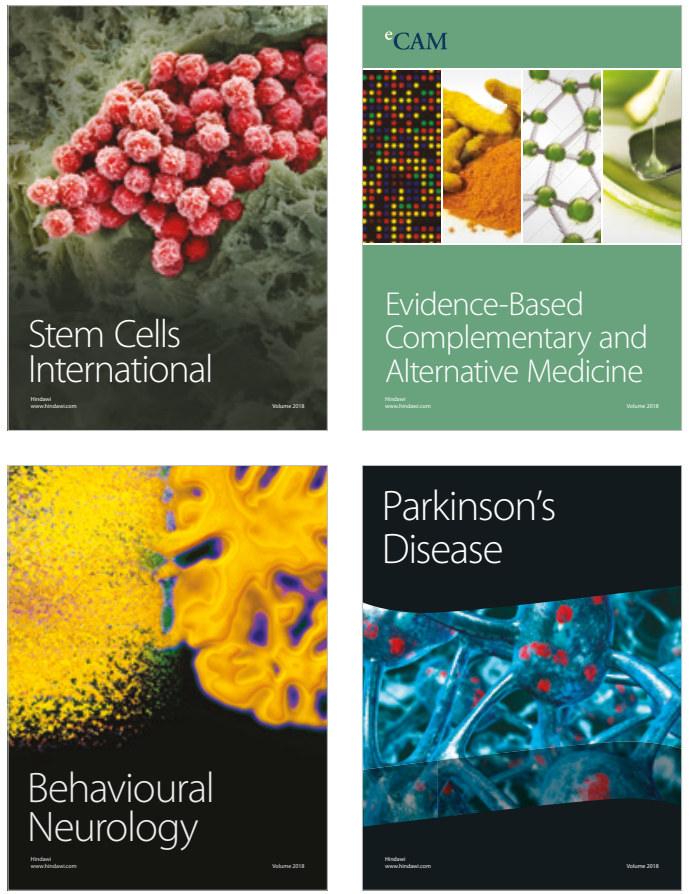

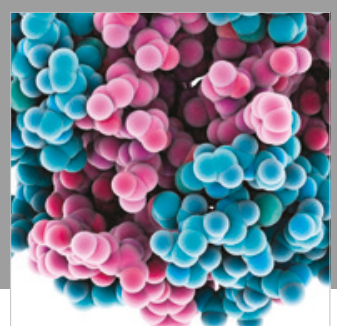

ournal of

Diabetes Research

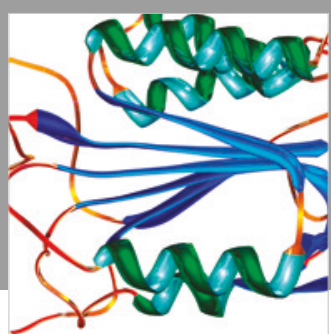

Disease Markers
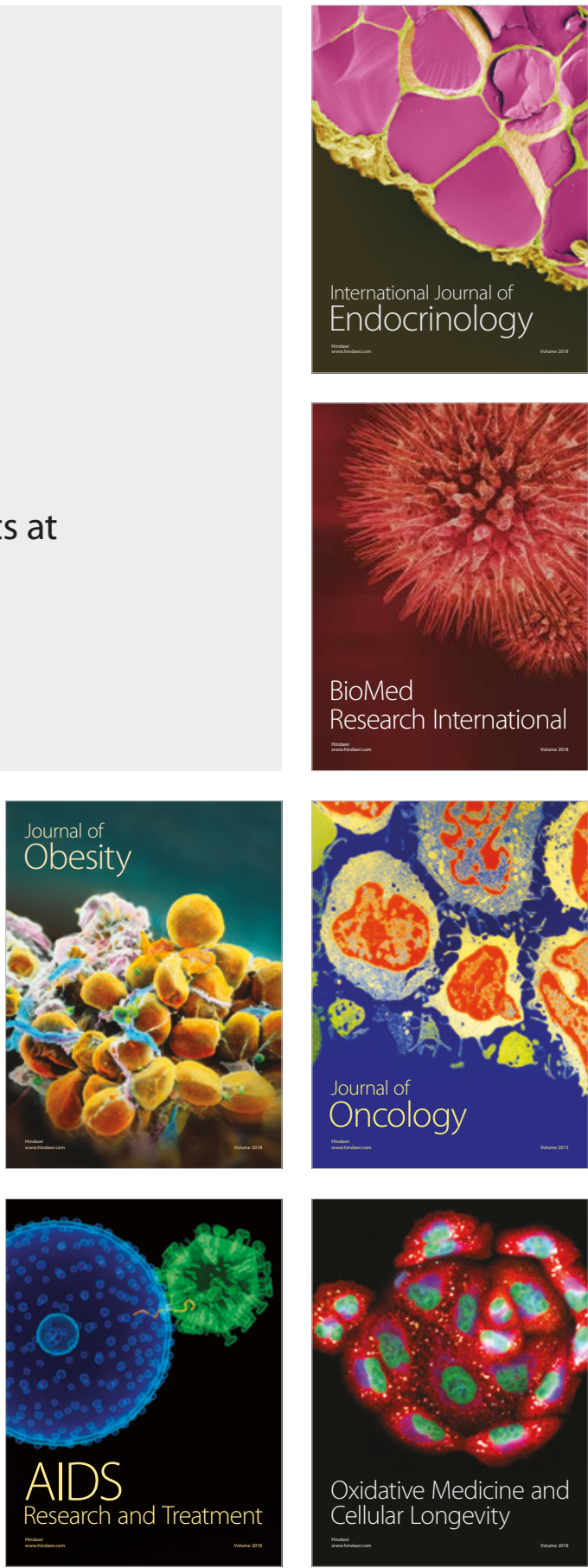